\title{
RELATIONSHIP BETWEEN BODY DISSATISFACTION, DEPRESSION AND ANXIETY AMONG YOUNG ADULTS
}

\section{MAHUM AZHAAR, MARIAM ANWAAR, MEHWISH DAWOOD, MAHEEN ALI, SIDRA SHOAIB}

\begin{abstract}
:
In the light of Self-Discrepancy Theory (SDT) and prevalence of body dissatisfaction in the Pakistani culture, the current correlational survey-based research design was aimed to explore the relationship between body dissatisfaction, depression, and anxiety among adult males and females. The hypotheses of the study were: (a) there will be a significant relationship between body dissatisfaction, anxiety and depression (b) there will be a significant difference in the level of body dissatisfaction between male and female adults. For this purpose, 343 unmarried young adults (Male $\mathrm{n}=168 \&$ Female $\mathrm{n}=175)$, age ranging from 16 -30 years $(M=22.07, S D=3.07)$ were recruited. The Body Dissatisfaction Scale, Patient Health Questionnaire, Generalized Anxiety Disorder Scale were administered on the participants. The results revealed a significant positive correlation $(p<.01)$ between body dissatisfaction depression $(r=0.27)$ and anxiety $(r=0.32)$ however, the relationship with depression was weak while the moderate relationship was found with anxiety. Additionally, anxiety was found to be a positive predictor of body dissatisfaction. There was further a significant difference $(p<.01)$ exhibited in the level of body dissatisfaction in males and females, where females had a higher level of body dissatisfaction as compared to males. Moreover, a significant difference $(p<.01)$ which signifies that females were more depressed than males. The current research has important implications for training programs, counseling, and psychotherapy.
\end{abstract}

\section{Keywords:}

Body Dissatisfaction, Anxiety, Depression, Young Adults

JEL Classification: $100,118,119$

\section{Authors:}

MAHUM AZHAAR, Institute of Professional Psychology, Karachi Campus, Bahria University, Pakistan, Email: mahum.azhaar@hotmail.com

MARIAM ANWAAR, Institute of Professional Psychology, Karachi Campus, Bahria University, Pakistan, Email: m.anwaar09@gmail.com

MEHWISH DAWOOD, Institute of Professional Psychology, Karachi Campus, Bahria University, Pakistan, Email: mehwishdawd@gmail.com

MAHEEN ALI, Institute of Professional Psychology, Karachi Campus, Bahria University, Pakistan, Email: aimuphi110@live.com

SIDRA SHOAIB, Institute of Professional Psychology, Karachi Campus, Bahria University, Pakistan, Email: sidrashoaib175@yahoo.com 


\section{Citation:}

MAHUM AZHAAR, MARIAM ANWAAR, MEHWISH DAWOOD, MAHEEN ALI, SIDRA SHOAIB (2020). Relationship between Body Dissatisfaction, Depression and Anxiety among Young Adults.

International Journal of Social Sciences, Vol. IX(2), pp. 21-39., 10.20472/SS.2020.9.2.002 


\section{INTRODUCTION}

The world has entered the era of modernization that has made radical changes to every cultural life. The emerging trends are incredibly attractive because of which viewers consistently want to enhance and shape their ideal body image, thus gradually becoming dissatisfied with their own physique. Assumingly, mass media has made its impact upon the global social beauty trends that are mainly portrayed through booming industries such as fashion, advertisement and entertainment industries.

Body image is one's subjective perception about their physical outlook which is based on their self-evaluation and remarks received from their surrounding environment. The word "Ideal" has been added to body image and is widely used as a representation of beauty criteria as the finest physical body (Martin, 2010). The ideal image has been found to be in contrast with the understanding of a healthy body image, influencing body dissatisfaction or satisfaction of one's body image.

Paradigms of a body image are still under the process of research. Bailey et al s study (2017) explored the negative perceptions of body image, especially among females, to which they faced a major challenge of defining body image as there were around 16 definitions enlisted. Despite these objective definitions, the perception of body image itself is highly influenced by biological, psychological and social factors. Furthermore, the components that easily affect the characterization of body image are Body Mass Index (Winter, Combs, \& Ward, 2018), Family Pressure (Goodman, 2005), Societal and Peer Pressure (Al-Sheyab, Gharaibeh \& Kheirallah, 2018), Media (Altaf, 2016), Social Media (Salomon \& Brown, 2019), Self-Esteem (Kim, 2018), and many more (Silva, Ferriani \& Viana, 2019).

Shoraka, Amirkafi, and Garrusi (2019) explored further factors involved in influencing body image and its related disorders in which body dissatisfaction was found to be an inclining factor for serious health complications. In public, there are misconceptions about achieving an ideal body image, especially females (Northrop, 2012) because of which individuals indulge in restricted diet, calorie deficient intake, excessive use of laxatives, supplements and overexercising (Shoraka, Amirkafi, \& Garrusi, 2019). This can lead to multiple complications related to their physical and psychological well-being (Griffiths et al., 2016; Lantz et al., 2018; LaportaHerrero et al., 2018).

Among sociocultural influences, there is little doubt about the power of television, social media, and other forms of mass media upon the concept of body image. Its profound portrayal of an attractive body for beauty ads, beaches, volleyball, basketball, wrestling has led to impacting the majority of the audiences' subjective concept of ideal body image (Bailey, Gammage, \& van Ingen, 2017; Uchôa et al., 2019). Being ultra-thin, to imitate a high-end fashion model, a celebrity, an actress/actor, athlete, body builders, or any of their favourite influencers are mostly one's ideal body image depiction (Morrison, Morrison, \& Hopkins, 2003; Brennan, Lalonde, \& Bain, 2010). If the standard of the perceived ideal body image is hardly or not at all achieved, it leads to body dissatisfaction (Martin, 2010).

Body Dissatisfaction has been defined as the discrepancy between the actual and ideal body weight and shape (Polivy \& Herman, 2002). It has been also defined as "negative subjective evaluations of one's physical body, such as figure, weight, stomach and hips" (Stice \& Shaw, 2002). It has become difficult to evaluate body dissatisfaction as some may want to change their body weight, but not the shape of their body and vice versa (Tiggemann, 2004). It is thus important to simplify the meaning of body dissatisfaction the moment it is being measured. For 
illustration, appropriate measures for body dissatisfaction should differentiate between measures of muscularity, such as weight gain (body muscle) and weight reduction (body fat) (Tiggemann, 2004). The interpretation of high body image is the overconcern of body appearance (Stice \& Shaw, 2002), whereas body dissatisfaction implies negative subjective perceptions and attitudes about one's body (Cash \& Pruzinsky, 2002).

In western societies, it has been found that body dissatisfaction is common among women (McLaren \& Kuh, 2004). They are dissatisfied with their bodies, primarily with their body weight, size, and shape. It has also been discovered that even at the age of seven, girls are dissatisfied with their body's. They tend to learn that thin is synonymous for beauty, happiness, success, and youth (Tiggemann, 2011). The message of being ideally thin is adopted, and people try their best to attain this goal.

Body Dissatisfaction is evident in females around $13.4 \%$ to $31.8 \%$ while $9 \%$ to $28.4 \%$ among males (Fallon, Harris, \& Johnson, 2013). Body dissatisfaction among males has been linked to several health-threatening behaviours related to increased muscle tone, such as the use of steroids and food supplements (Cafri et al., 2005).

Higgins (1987) formalized a model termed as the Self-Discrepancy Theory (SDT) which explains the nature of ideal self with respect to its position in mind and its effect on an individual's selfconcept and behaviour. The model further explains the self in three domains; the actual self in which the individual reflects his or her own perception of attributes. The other two domains can further stimulate the self as "ideal self", referring to the self that wants to be achieved or the self which the person admires to have; "The ought self" are attributes that are believed to be a responsibility to hold by the self because it is required by either a significant other or society's expectations. Actual and ideal self-discrepancy is said to cause dejection related states which furthers results as dissatisfaction and depression. On the other hand, the actual and ought selfdiscrepancy causes agitation related emotional states that can be explained in terms of anxiety and guilt over incapability of following certain standards. In consequence, certain behaviours are elicited that engage an individual's behavior to remove, or at most, fill the gap of these discrepancies. (Higgins, 1987; Vartanian, 2012).

The significance of SDT and body perception is dependent on the idea that cultural norms set standards of attractiveness. For example, the common and most widely set standards for women are thin, lean and for men, muscular physique. Without the use of tough measures, such as cosmetic surgery, starvation techniques, these standards are difficult and unrealistically achievable for mainstream people. Therefore, body image self-discrepancy will occur if the actual self is compared with the ideal promoted by society because people will always fall short of this standard thus creating psychological conflicts (Vartanian, 2012).

Several researches across the globe have discussed the relationship between body dissatisfaction, anxiety and depression. These contain distinct psychological types such as depressive moods (Stice et al., 2000), anxiety (Ivezaj et al., 2010), social physique anxiety (Brunet et al., 2010), and social phobia in both genders (Paxton et al., 2006). Wertheim, Koerner, and Paxton (2001) examined longitudinal predictors of future eating problems in 435 female adolescents and they found that body dissatisfaction, depression, and weight-related teasing had a significant role to play in eating and bulimic tendencies. Dislike for the body image has enforced women to the extremes of serious eating disorders and depression which further leads them to attempt or commit suicide (Pompili et al., 2006). It's effect on self-esteem has 
been observed because of negative perception of their body image which results in psychological distress (Duchesne et al., 2017).

Vannucci and Ohannessian (2017) examined the baseline body image dissatisfaction (BID) among 581 adolescents from U.S. Public High Schools through self-report questionnaires at 3 annual evaluations. The results of the study indicated higher body dissatisfaction associated with a greater sum of symptoms with Generalized Anxiety Disorder (GAD), Panic Disorder (PD) and Social Anxiety Disorder (SAD) but no effect on Separation Anxiety Disorder (SEP). It was also observed to have an association of Higher baseline BID with attenuated decreases in SAD symptoms across time $(p=.001)$. Results suggest that BID is associated with concurrent symptoms of multiple anxiety disorders.

In recent studies, body dissatisfaction has found to be immensely prevalent among Asian Countries (Tsai, Curbow \& Heinberg, 2003; Chng \& Fassnacht, 2016; Izydorczyk et al., 2020). Khor et al. (2009) discovered higher body dissatisfaction among females who desired for a thinner body figure as compared to males. As far as body size is concerned, males desired for a muscular body while females preferred to have thin, small body size. Furthermore, study evaluated the negative effect of poor body image leading to unhealthy dietary routine and eating behaviors.

Asian Countries contain diverse cultures and lifestyles which are highly influenced by their sociocultural factors and mass media (Omori et al.,2017; Dogan et al., 2018). Therefore, it is imperative to discern the aspects of body dissatisfaction in the context of the Pakistani culture. Such literatures were explored and one of them being Memon et al. (2012) in which his findings stated that female medical students are more prone to developing eating disorders in contrast to male medical students. Suhail (2002) highlighted prevalence in view of eating disorders, in Lahore, due to body shape and depression. They found that from a total sample size of 111 participants, $59 \%$ of the individuals with normal body weight and $21 \%$ of the females with underweight considered themselves as overweight. The remaining sample was found to meet the criteria of eating disorders. This is considered to be alarming because such experiences are highly influenced by the western lifestyle, adding to the exposure of beauty standards set by the native culture. It also sheds light on the misconception that $80 \%$ of the population believed in being overweight while they were not. Moreover, Khan et al. (2011) found negative impact of media on body image of university students in Pakistan. Their findings supported that males scored higher on body dissatisfaction than females.

Due to limited literature availability in Pakistan about predicting factors of body dissatisfaction, the current research may assist in identifying pre-clinical symptoms, in ordinary terms "redflags", that could manifest itself into a clinical disorder. These red flags or early signs entails one's subjective experience of discrepancy in their ought self and ideal self. These could include feelings of worthlessness, hopelessness, over or lack of eating, apprehensions of weight gain, negative self comments about body shape and weight. If these symptoms persist over time, they may take the form of depression and anxiety symptoms, transforming the initial perception of poor body image into body dissatisfaction. Both symptoms and body dissatisfaction fuelling one another in a circular motion can lead to the onset of psychiatric or psychological disorders. Such phenomenon was not explored in the Pakistani research but there has been evidence available in the international studies that poor body image was related to increase in psychological symptoms such as distress (Chang et al., 2014), depression (Himelein, \& Thatcher, 2006; Paans et al., 2018), anxiety (Kogure et al., 2019) and other psychiatric disorders (Manaf, Saravanan \& ZuhrAh,2016; Blostein, Assari \& Caldwell, 2017). If poor body image is 
intervened at an early stage, it can be helpful in facilitating individuals with negative associated feelings with the body.

Thus, the aim of this research paper was to discover the relationship between body dissatisfaction, depression and anxiety among young adult males and females. It's research objectives are as follows:

- To explore the relationship among body dissatisfaction, depression and anxiety symptoms

- To explore the predictive role of depression and anxiety on body dissatisfaction

- To discover the differential level of body dissatisfaction between males and females

The hypotheses of this study are:

a) There would be a significant relationship between body dissatisfaction, depression and anxiety.

b) There would be a significant difference in the level of body dissatisfaction between male and female young adults.

\section{METHODOLOGY}

This survey-based research study was conducted on 343 young adults (i.e., 168 males and 175 females) of Karachi which were recruited through convenient sampling. As per the inclusion criteria, participants were aged from 18 to 30 years, unmarried and were able to understand Urdu. The reported subjects have a variety of educational background, including completion of secondary school $(10.1 \%)$, high school $(18.7 \%)$, graduates $(6.4 \%)$, bachelors $(52.5 \%)$ and master's degree (10.5\%). Participants' scores on the body-mass index (BMI) ranged from 14 to 39 with a mean of $21.97 \pm 4.22$.

To measure the level of body dissatisfaction among young adults, Body Dissatisfaction Scale (BDS) (Tariq \& ljaz, 2015) was used. The questionnaire consisted of 26 items on which the participants were asked to state the extent to which they are satisfied with their bodies/physical appearance. The Cronbach Alpha of this scale was good $(\alpha=.867)$. In BDS, the scores of 27 , 33, 39, and 52 represented borderline, mild, moderate and severe body dissatisfaction, respectively. The second scale was The Patient Health Questionnaire (PHQ-9) is a selfadministered version of the PRIME-MD diagnostic instrument (Ahmad et al, 2018). The PHQ-9 is a 9-item depression module from the Full PHQ (Spitzer et al, 1990) and the Cronbach Alpha falls in acceptable range ( $\alpha=.787)$. In PHQ- 9 scores, 5 represents mild, 10 represents moderate, 15 signified moderately severe, and 20 signified the level as severe. To measure anxiety, the Generalized Anxiety Disorder (GAD-7) questionnaire was selected (Ahmad et al, 2017). It is a seven-item, self-report anxiety questionnaire designed to assess the patient's health status during the previous 2 weeks and the Cronbach's Alpha was acceptable ( $\alpha=.737)$. In GAD-7, scores of 6 represents mild, 11 represents moderate, and 16 signified the level as severe.

The sample completed a set of self-administered, paper-pencil questionnaires anonymously which included the informed consent form, demographics form, BDS, PHQ-9 and GAD-7 all translated in Urdu. The time it took to fill the questionnaire set by each individual was 10 to 15 minutes after which they were thanked for their participation and cooperation. The data was collected and analysed through IBM Statistical Package for Social Analysis Software (SPSS) Version 21. 


\section{RESULTS}

Table 1 Demographics Descriptive Statistics of the Participants

\begin{tabular}{lcccc}
\hline \multicolumn{1}{c}{ Variables } & N & M & SD & $\%$ \\
\hline Age & 343 & 22.07 & 3.07 & \\
Weight(Kgs) & 343 & 60.87 & 13.53 & \\
Height(cm) & 343 & 166.2 & 8.88 & \\
Body Mass Index & 343 & 21.97 & 4.22 & \\
Gender & & & & 49 \\
$\quad$ Male & 168 & & 51 \\
$\quad$ Female & 175 & & & 16 \\
Ranges of BMI & & & & 66.8 \\
$\quad$ Underweight & 55 & & & 12 \\
$\quad$ Healthy Weight & 229 & & 5.2 \\
$\quad$ Overweight & 41 & & & \\
$\quad$ Obese & 18 & & & \\
\hline
\end{tabular}

Table \# 1 provides the statistical description of mean and standard deviation of Age, weight, height, $\mathrm{BMI}$, Gender and Ranges of BMI.

\section{Table 2}

Descriptive statistics \& univariate normality of study variables $(N=343)$

\begin{tabular}{lcccc}
\hline \multicolumn{1}{c}{ Variables } & $M$ & $S D$ & Sk & $\mathrm{K}$ \\
\hline Body Dissatisfaction & 17.1 & 13.31 & 0.87 & 0.18 \\
Depression & 6.15 & 4.71 & 0.79 & 0.18 \\
Anxiety & 5.75 & 4.39 & 1.20 & 3.61 \\
\hline
\end{tabular}

Table 2 displays the overall spread of data for each variable in accordance with their mean $(M)$, standard deviation $(S D)$, skewness $(S k)$ and kurtosis $(K)$.

\section{Table 3}

Correlation among Body Dissatisfaction, Depression and Anxiety ( $N=343)$

\begin{tabular}{lccc}
\hline & Body & & \\
& Dissatisfaction & Depression & Anxiety \\
\hline Body Dissatisfaction & - & $.27^{* *}$ & $.34^{* *}$ \\
Depression & & - & $.58^{* *}$ \\
Anxiety & & & - \\
${ }^{* *} p<0.01$ & &
\end{tabular}

The above results in Table 3 reveal body dissatisfaction to be positively significantly correlated with depression as $r=.27(p<0.01)$, and anxiety with $r=.34(p<0.01)$. However, the magnitude of the relation is weak, with anxiety being more impactful in comparison to depression, upon body dissatisfaction. 


\section{Table 4}

Simple linear regression showing the impact of Anxiety on Body Dissatisfaction ( $N=343)$

Body Dissatisfaction

\begin{tabular}{llll}
\cline { 2 - 4 } Predictors & $B$ & $\mathrm{R}^{2}$ & $95 \% \mathrm{Cl}$ \\
\hline Anxiety & $.34^{\star \star}$ & .11 & {$[.19,1.44]$} \\
\hline${ }^{\star \star} p<0.01$ & & &
\end{tabular}

Table 4 shows the statistical analysis of linear regression. It was calculated to predict anxiety based on body dissatisfaction and it was found that body dissatisfaction significantly predicted anxiety in the sample $(\beta=.32, p<0.01)$.

\section{Table 5}

Mean standard deviation and t-value for gender on body dissatisfaction, Depression and Anxiety

\begin{tabular}{|c|c|c|c|c|c|c|c|}
\hline & & $\begin{array}{l}\text { le } \\
67)\end{array}$ & $\begin{array}{l}\text { Fel } \\
(n=\end{array}$ & $\begin{array}{l}\text { ale } \\
75)\end{array}$ & & & $\begin{array}{l}\text { Cohen' } \\
s d\end{array}$ \\
\hline & $\mathrm{M}$ & SD & $\bar{M}$ & SD & $t$ & $p$ & \\
\hline Body Dissatisfaction & 14.21 & 12.32 & 19.86 & 13.67 & -4.01 & $.001^{*}$ & .61 \\
\hline Depression & 5.38 & 4.62 & 6.88 & 4.69 & -2.96 & $.003^{*}$ & .32 \\
\hline Anxiety & 5.29 & 4.51 & 6.20 & 4.23 & -1.90 & .057 & - \\
\hline
\end{tabular}

In Table 5 the independent sample t-test demonstrates the comparison of body dissatisfaction, depression and anxiety among gender. There was a significant difference in the mean scores for body dissatisfaction between male $(M=14.21$, $S D=12.32)$ and female $(M=19.86, S D=13.676)$ conditions; $t=-4.010,(p<.01)$. Thus, the result suggests that females have more body dissatisfaction than males. Furthermore, the mean scores for depression were also found to be significant $(p<.01)$ among females as compared to males. However, there was no significant result for anxiety among males and females. 


\section{Table 6}

Chi-Square Test of Independence with Levels of Body Dissatisfaction Scale (BDS) and Body Mass Index (BMI) with Gender

\begin{tabular}{lccc}
\hline Levels of BDS & Male & Female & P value \\
\hline No Body Dissatisfaction & 146 & 125 & \\
Borderline & 6 & 16 & .011 \\
Mild & 8 & 14 & \\
Moderate & 7 & 15 & \\
Severe & 1 & 5 & P Value \\
\hline Ranges of BMI & Male & Female & \\
\hline Underweight & 21 & 34 & .000 \\
Healthy Weight & 101 & 128 & \\
Overweight & 29 & 12 & \\
Obese Range & 17 & 1 & \\
\hline
\end{tabular}

Table 6 explains the association between gender and levels of body dissatisfaction and body mass index. The results were found to be significant indicating that there is an association of gender with levels of $\operatorname{BDS}, X^{2}(4, N=343)=13.059, p=.01$ and BMI, $X^{2}$ $(3, N=343)=27.396, p=.00$.

\section{DISCUSSION}

Beauty has its own definition, it varies from culture to culture, and generation to generation. The increasing outlook of beauty standards is causing havoc among the general population. In Asian Countries, like Pakistan, being fair complexion and thin figures are considered as an ideal body goal as women feel societal and media pressure from their surrounding environment (Franchina, \& Coco, 2018)

This section provides insight and plausible explanations in the relation of body dissatisfaction, depression and anxiety among young adults. The results of the current study shows that there is a significant positive relationship of body dissatisfaction with depression and anxiety. However, the magnitude of the relation of depression with body dissatisfaction appeared to be weak while the relation of anxiety with body dissatisfaction appeared to be moderate. 
Likewise, Levinson and Rodebaugh (2014) have indicated that the mere concern of body dissatisfaction appears to be the trigger of several psychological problems including anxiety and depression. General findings have also indicated that body dissatisfaction is connected with different psychological difficulties which include depressive mood (Stice et al., 2000), anxiety (Ivezaj et al., 2010) and low self-esteem (Duchesne et al., 2017). One possible reason behind this is dissatisfaction with weight gain and body shape (Mahmud \& Crittenden, 2007; Råberg et al., 2010). Furthermore similar studies also reported that females are more concerned about being overweight rather than underweight as they are more apprehensive to gain weight, while middle aged males were disturbed because of the shape of their body(del Mar Bibiloni et al., 2017). This also explains the perception of maintaining an ideal body image which conflicts with the actual self thus resulting in early signs of anxiety, depression and other psychological distresses (del Mar Bibiloni et al., 2017).

Hamilton (2008) stated that the low body image negatively correlates with depression which provides evidence for the relationship between body dissatisfaction and depression. Furthermore, the study results are in accordance with the current study that they show a weak correlation.

Previously, mass media globally shaped the concept of beauty standards (Swinson, 2011). They have set certain criterias which are considered to be unreasonable for one's body image (Khan et al., 2011). Jalees and de Run (2014) explains a positive association between media exposure and body image and having a negative influence on self-esteem.Thus, according to Van Den Berg et al. (2007), failure to achieve such ideal body type resulted in high depression.

However, in recent years, the skinny body concept is now transforming to take on the approach of having models with fuller body shape. One of the existing proofs are the contemporary top media industries being more inclusive, open and accepting to diverse beauty standards such as Elle portraying a Sudanese model on their front cover. Dove's \#ShowUs campaigns on the actual self of its consumers. Nike accommodating shoes for those with prosthetics (Givhan \& Morales, 2020). Based on these novel refocus of media campaigns, there may be a decline in psychological distresses (Hamilton, 2008). In addition to this, experimental researches have proposed that brief exposure to social media such as Facebook does not influence negatively on the appearance of a female (Fardouly \& Vartanian,2016).

Based on the above discussion, one of the contributing factors to the weak relationship of the first hypothesis can be due to promotional campaigns for accepting the actual self and several health awareness programs aired through media and other social resources. This was reported by Curtis and Loomans (2014) as the significance of a healthy lifestyle has been vastly promoted which encompasses physical exercises, nutritional diet plans and other health interventions. At a macroscopic level, this has facilitated in decreasing body dissatisfaction.

It is necessary for individuals to have a sense of contentment with their physique. This comfort level develops through the primary and secondary support systems, that is, family and friends. If such support systems engage in communication of negative comments such as fat talk, constant teasing, comparisons and promoting the 'thin ideal', it causes extreme self-scrutiny leading towards high levels of anxiety (Curtis \& Loomans, 2014). Furthermore, collectivistic culture has its own influences in the form of societal pressure, imposing expectations and enforcing individuals to excel in all domains of life. The period itself is distressing that all the focus shifts to other major stressors rather than their body image. Such as Cheung, Cheung \& $\mathrm{Wu}$ (2014) supporting this notion and stating that anxiety is highly triggered by career 
unreadiness which is in reference to the negative effect of authoritarian parenting. In pursuit of their career establishment, young adults experience immense pressure to achieve their goals, therefore, prioritising work over body image. These arguments may explain anxiety being a stronger predictor but at the same time a weak association with body dissatisfaction.

The findings for the second hypothesis verified that there was a significant relationship between body dissatisfaction and gender, $X^{2}(4, N=343)=13.059, p=.01$. This study supports that females have reported to be more dissatisfied with their bodies than males. The prevalence of body dissatisfaction has found to be prevalent among females with increased onset risk of psychological and psychiatric disorders (Chen, Gao, \& Jackson, 2007; Scherr, Ferraro \& Weatherly, 2010; Kwan et al., 2018). A qualitative study explored the main themes related to social media negative influence on poor body image such as efforts to select an ideal, best picture to post, self-promotion placing importance on getting feedback as a channel to engage with the audience. This results in affecting body image by idealising exquisite goods to seek public approval and comparing themselves with ideals (Baker, Ferszt, \& Breines, 2019).

However, Males were found to be more significant in the range of overweight and obese as compared to females, $X^{2}(3, N=343)=27.396, p=.00$. This explains that there is a constant pressure on females, expected to look beautiful, in weddings especially for brides and bridesmaids for which most of them have been told to lose weight and begin dieting (Prichard, \& Tiggemann, 2008). They also added that females who were told to lose weight and do diet, gained significant weight after their wedding as compared to those who were not told to lose weight (Prichard, \& Tiggemann, 2014). Similarly, Prichard et al. (2015) also highlights the importance of weight in the selection of intimate partners.

Among Asian young adults, a strong association has been found between parental comments with body dissatisfaction especially among females as compared to males (Chng, \& Fassnacht, 2016). In India, females struggle with the issues of body image because of societal pressure, an increase in engagement of western outlook and influence of Bollywood Industry contributing as a sociocultural factor(Kapadia, 2009). Furthermore, there is a strong marital preference based on skin color. Abdullah's (2018) study explained a brief account about males' preferences for their mate selection which included slim size with good appearances reflecting freshness, regardless of their education, being unemployed and regardless of their marital status that is even being divorced.

Researches have supported men to be more satisfied with their physical appearance and they are not preoccupied with their body alterations (Muth \& Cash 1997; Doyle \& Engeln 2014). However, Barnes et al. (2020) findings yielded the prevalence of body dissatisfaction with anxiety and depression among males emphasizing on concerns of thinness and masculinity. While for Asian females, having a thin ideal body size is favourable as compared to western females (Wardle et al., 1993; Kim \& Lee, 2019). Even in Iranian culture body dissatisfaction was found to be higher to other Asian countries (Garrusi \& Baneshi, 2017). Demographic variables such as age, sex, marital status and body mass index were found in association with body dissatisfaction. Similar results were found in the current study which illustrated that gender differences were $(p<.01)$ significant (Garrusi \& Baneshi, 2017).

Darwin's Theory of Evolution explains the process of sexual mate selection which leads to the survival of the fittest. One of the important factors in selecting the perfect mate is the physical appearance, which is the key component in the sexual attraction. For this to take place, males prefer the hour glass shape and young skin of a female to maintain the relationship and secure 
a healthy generation (Barber, 2013). These primitive biological instincts suggest that most women are dissatisfied with their bodies, mainly with weight, size, and shape as from an early age they have learned that thin is synonymous for beauty, happiness, success, and youth (Tiggemann, 2011). Zachrisson and Skardrud (2010) traces back body dissatisfaction in women to their early childhood where mothers tend to rigorously raise their daughters to have an appropriate appearance, compared to boys, due to pressure of societal scrutiny. This leads to volatile attachments (Zachrisson and Skardrud, 2010), emotional dysregulation, and the development of psychological symptoms such as eating disorders (Burns et al., 2012).

On the other hand, Triggerman (2011) does state that there is an increasing evidence of body dissatisfaction in males. Primus (2014) illuminates that males have raised the bars of scrutinizing their self-image based on the $21^{\text {st }}$ century's emerging trends of men and boys to be attractive by exhibiting handsome male models and actors in products, commercials and movies.

Pakistani media has reinforced the concept of perfect women through television drama serials which reflect patriarchal systems. They have presented the female heroine as attractive, modest, slim, fair, young age between 18 to 25 years. These physical characteristics are the perfect standards set by the media which has been perceived by the society as natural beauty (Ashfaq \& Shafiq, 2018).

Body image has a different representation between both genders which Benuto et al. (2007) qualitatively explored. He stated that females strive for a thin body however, male concerns were divided into 2 categories, that is, to lose or to gain weight. Furthermore, men were increasingly disturbed with reference to their specific body areas such as chest, and shoulders which they desire to be broader. However, both genders show concerns with their increase of BMI (Gillen \& Lefkowitz, 2012).

Shaheen et al. (2016) emphasized that in Pakistan, the society has engrossed ideals of thinness in women and muscular bodies among males through the concept of physical attractiveness. Furthermore, it was highlighted that nowadays men are more concerned about their physical fitness and engaged in certain activities to improve it rather than females who are dissatisfied from their different body parts. The stated evidence suggests that people are now focusing on maintaining their lifestyle by engaging in healthy activities, however, there is a certain level of stigma attached to being perfect in shape which tends to create turbulence.

Additionally, it was found that females were significantly more depressed as compared to males. As the relation with body dissatisfaction was weak, thus, it can not be assumed that individuals were depressed due to body dissatisfaction. Studies have shown that the main reason for depression can be because of demographics and psychosocial factors such as self-esteem, lack of emotional support, and gender (Farrer et al., 2016).

Likewise, increased weight and obesity has been considered as an utmost factor in the body dissatisfaction (Bucchianeri et al., 2013) that studies have shown to have association with depression and anxiety (Chu \& Mehrzad, 2020). This is further explained by socio cultural model theories, emphasizing a lot of pressure on maintaining thin as ideal weight (Boone, Soenens \& Braet, 2011) however, Rodgers (2016) proposed a healthy weight maintenance leading to controlling by means of going on healthy diets and exercises. Though, It may keep the brain preoccupied with the body and destabilize eating habits. 


\section{IMPLICATIONS}

This study enlightens the associating variables and predictors of body dissatisfaction which can further help in providing an outlook to focus on the early signs and symptoms of depression and anxiety.

- Aid mental health practitioners in designing preventive measures and inhibiting the early manifestations of psychological disorders such as eating disorders.

- Further investigate the relationship in the Pakistani culture through longitudinal research design.

- Exercise and proper diet guidance to the young population should be given to avoid the prevalence of body dissatisfaction.

- Psychological interventions that target negative social evaluation fears can be designed which may help prevent body dissatisfaction and eating disorders.

- Media campaigns on healthy weight programs are important to provide awareness and prevent the onset of chronic illnesses and obesity.

\section{CONCLUSION}

The study shows that there is a positive significant relationship between body dissatisfaction, depression and anxiety. However, the relation of body dissatisfaction was found to be weak while the relation of anxiety with body dissatisfaction was found to be moderate. The study determines that anxiety is a predictor of body dissatisfaction and shows a relationship with body dissatisfaction. In gender comparison, females have more body dissatisfaction than males despite significant differences in the ranges of BMI, illustrating that males were overweight and obese in contrast to females who were healthy but still dissatisfied

Additionally, it was found that females were more depressed as compared to males. Due to the weak relation of depression and body dissatisfaction, it cannot be concluded that depression would be a good predictor of body dissatisfaction while anxiety has found to reflect moderate level of relationship considering this as a good predictor since anxiety itself communicates future anticipation of concerns of body weight. However, it is important to keep other factors in mind that could influence anxiety, for example at this specific age of young adulthood, there tends to be a concern about achieving independence thus rigorously focusing on university performance and obtaining a financially stable job.

\section{REFERENCES}

Abdullah, H. S. (2018). Gender differences in mate selection criteria among Malaysian undergraduate students. Sarjana, 26(2), 33-50.

Ahmad, S., Hussain, S., Akhtar, F., \& Shah, F. S. (2018). Urdu translation and validation of PHQ-9, a reliable identification, severity and treatment outcome tool for depression. JPMA. The Journal of the Pakistan Medical Association, 68(8), 1166-1170.

Ahmad, S., Hussain, S., Shah, F. S., \& Akhtar, F. (2017). Urdu translation and validation of GAD-7: A screening and rating tool for anxiety symptoms in primary health care. JPMA. The Journal of the Pakistan Medical Association, 67(10), 1536-1540.

Al-Sheyab, N. A., Gharaibeh, T., \& Kheirallah, K. (2018). Relationship between peer pressure and risk of eating disorders among adolescents in Jordan. Journal of obesity, 2018. https://doi.org/10.1155/2018/7309878 
Altaf, H. (2016) Body image dissatisfaction as social issue created through fear marketing in personal care products.

Annie-Pier Duchesne, Jacinthe Dion, Daniel Lalande, Catherine Bégin, Claudie Émond, Gilles Lalande, Pierre McDuff. Body dissatisfaction and psychological distress in adolescents: Is self-esteem a mediator? J Health Psychol. 2017 Oct;22(12):1563-1569. https://doi.org/10.1177/1359105316631196

Ashfaq, A., \& Shafiq, Z. (2018). Contested Images of'Perfect Women'in Pakistani Television Dramas. Journal of the Research Society of Pakistan, 55(1). https://doi.org/10.21162/PAKJAS/18.6547

Bailey, K. A., Gammage, K. L., \& van Ingen, C. (2017). How do you define body image? Exploring conceptual gaps in understandings of body image at an exercise facility. Body image, 23, 69-79. https://doi.org/10.1016/j.bodyim.2017.08.003

Barber, N. (2013, May 02) Why Women Feel Bad About Their Appearance: Lookism does not explain body image discontent. Retrieved from: https://www.psychologytoday.com/blog/the-humanbeast/201305/why-women-feel-bad-about-their-appearance

Barnes, M., Abhyankar, P., Dimova, E., \& Best, C. (2020). Associations between body dissatisfaction and self-reported anxiety and depression in otherwise healthy men: A systematic review and meta-analysis. PloS one, 15(2), e0229268. https://doi.org/10.1371/journal.pone.0229268

Benuto L., Haboush A. \& Jones-Forrester S. (2007). Compensatory efforts for body dissatisfaction; some gender and ethnic differences. The new school Psychology Bulletin,5(2):19-25. https://doi.org/10.1037/e741502011-003

Blostein, F., Assari, S., \& Caldwell, C. H. (2017). Gender and ethnic differences in the association between body image dissatisfaction and binge eating disorder among Blacks. Journal of racial and ethnic health disparities, 4(4), 529-538. https://doi.org/10.1007/s40615-016-0255-7

Boone, L., Soenens, B., \& Braet, C. (2011). Perfectionism, body dissatisfaction, and bulimic symptoms: The intervening role of perceived pressure to be thin and thin ideal internalization. Journal of Social and Clinical Psychology, 30(10), 1043-1068. https://doi.org/10.1521/jscp.2011.30.10.1043

Brennan, M. A., Lalonde, C. E., \& Bain, J. L. (2010). Body image perceptions: Do gender differences exist. Psi Chi Journal of Undergraduate Research, 15(3), 130-138. https://doi.org/10.24839/10894136.JN15.3.130

Brunet, J., Sabiston, C. M., Dorsch, K. D., \& McCreary, D. R. (2010). Exploring a model linking social physique anxiety, drive for muscularity, drive for thinness and self-esteem among adolescent boys and girls. Body image, 7(2), 137-142. https://doi.org/10.1016/j.bodyim.2009.11.004

Bucchianeri, M. M., Arikian, A. J., Hannan, P. J., Eisenberg, M. E., \& Neumark-Sztainer, D. (2013). Body dissatisfaction from adolescence to young adulthood: Findings from a 10-year longitudinal study. Body image, 10(1), 1-7. https://doi.org/10.1016/j.bodyim.2012.09.001

Burns, E. E., Fischer, S., Jackson, J., \& Harding, H.G. (2012). Deficits in emotion regulation mediate the relationship between childhood abuse and later eating disorder symptoms. Journal of Child Abuse \& Neglect, 36, 32- 39. https://doi.org/10.1016/j.chiabu.2011.08.005

Cafri, G., Yamamiya, Y., Brannick, M., \& Thompson, J. K. (2005). The influence of sociocultural factors on body image: A meta-analysis. Clinical Psychology: Science and Practice, 12, 421-433. https://doi.org/10.1093/clipsy.bpi053

Cash, T. F., \& Pruzinsky, T. (Eds.) (2002). Body image: A handbook of theory, research, and clinical practice. New York: Guilford

Chang, O., Choi, E. K., Kim, I. R., Nam, S. J., Lee, J. E., Lee, S. K., ... \& Cho, J. (2014). Association between socioeconomic status and altered appearance distress, body image, and quality of life 
among breast cancer patients. Asian Pac J Cancer Prev, 15(20), 8607-12. https://doi.org/10.7314/APJCP.2014.15.20.8607

Cheung, C. K., Cheung, H. Y., \& Wu, J. (2014). Career unreadiness in relation to anxiety and authoritarian parenting among undergraduates. International journal of adolescence and youth, 19(3), 336-349. https://doi.org/10.1080/02673843.2014.928784

Chng, S. C., \& Fassnacht, D. B. (2016). Parental comments: Relationship with gender, body dissatisfaction, and disordered eating in Asian young adults. Body Image, 16, 93-99. https://doi.org/10.1016/j.bodyim.2015.12.001

Chng, S. C., \& Fassnacht, D. B. (2016). Parental comments: Relationship with gender, body dissatisfaction, and disordered eating in Asian young adults. Body Image, 16, 93-99. https://doi.org/10.1016/j.bodyim.2015.12.001

Chu, J., \& Mehrzad, R. (2020). Psychosocial factors and outcomes of obesity. In Obesity (pp. 85-97). Elsevier. https://doi.org/10.1016/B978-0-12-818839-2.00007-7

Curtis, C., \& Loomans, C. (2014). Friends, family, and their influence on body image dissatisfaction. Women's Studies Journal, 28(2), 39.

del Mar Bibiloni, M., Coll, J. L., Pich, J., Pons, A., \& Tur, J. A. (2017). Body image satisfaction and weight concerns among a Mediterranean adult population. BMC public health, 17(1), 39. https://doi.org/10.1186/s12889-016-3919-7

Dogan, O., Bayhan, P., Yukselen, A., \& Isitan, S. (2018). Body image in adolescents and its relationship to socio-cultural factors. Educational sciences: theory \& practice, 18(3).

Doyle, D. M., \& Engeln, R. (2014). Body size moderates the association between gay community identification and body image disturbance. Psychology of Sexual Orientation and Gender Diversity, 1(3), 279. https://doi.org/10.1037/sgd0000049

Duchesne, A. P., Dion, J., Lalande, D., Bégin, C., Émond, C., Lalande, G., \& McDuff, P. (2017). Body dissatisfaction and psychological distress in adolescents: Is self-esteem a mediator?. Journal of health psychology, 22(12), 1563-1569 doi. 10.1177/1359105316631196

Farrer, L. M., Gulliver, A., Bennett, K., Fassnacht, D. B., \& Griffiths, K. M. (2016). Demographic and psychosocial predictors of major depression and generalised anxiety disorder in Australian university students. BMC psychiatry, 16(1), 241. https://doi.org/10.1186/s12888-016-0961-z

Franchina, V., \& Coco, G. L. (2018). The influence of social media use on body image concerns. International Journal of Psychoanalysis and Education, 10(1), 5-14.

Garrusi, B., \& Baneshi, M. R. (2017). Body dissatisfaction among Iranian youth and adults. Cadernos de Saude Publica, 33, e00024516. https://doi.org/10.1590/0102-311x00024516

Garrusi, B., \& Baneshi, M. R. (2017). Body dissatisfaction among Iranian youth and adults. Cadernos de Saude Publica, 33, e00024516. https://doi.org/10.1590/0102-311x00024516

Gillen, M. M., \& Lefkowitz, E. S. (2012). Gender and racial/ethnic differences in body image development among college students. Body Image, 9(1), 126-130. https://doi.org/10.1016/j.bodyim.2011.09.004

Givhan, E., \& Morales, P. (2020). The idea of beauty is always shifting. Today, it's more inclusive than ever. Retrieved from https://www.nationalgeographic.com/magazine/2020/02/beauty-todaycelebrates-all-social-media-plays-a-role-feature/

Goodman, J. R. (2005). Mapping the sea of eating disorders: A structural equation model of how peers, family, and media influence body image and eating disorders. Visual Communication Quarterly, 12(3-4), 194-213. https://doi.org/10.1207/s15551407vcq1203\&4_7 
Griffiths, S., Hay, P., Mitchison, D., Mond, J. M., McLean, S. A., Rodgers, B., ... \& Paxton, S. J. (2016). Sex differences in the relationships between body dissatisfaction, quality of life and psychological distress. Australian and New Zealand Journal of Public Health, 40(6), 518-522. https://doi.org/10.1111/1753-6405.12538

Hamilton, S. R. (2008). A relationship between perceived body image and depression: How college women see themselves may affect depression. Student Journal of Psychological Science, 1(1), 13-20.

Higgins, E. T. (1987). Self-discrepancy: a theory relating self and affect. Psychological review, 94(3), 319. https://doi.org/10.1037/0033-295X.94.3.319

Himelein, M. J., \& Thatcher, S. S. (2006). Depression and body image among women with polycystic ovary syndrome. Journal of health psychology, 11(4), 613-625. https://doi.org/10.1177/1359105306065021

Ivezaj, V., Saules, K. K., Hoodin, F., Alschuler, K., Angelella, N. E., Collings, A. S., ... \& Wiedemann, A. A. (2010). The relationship between binge eating and weight status on depression, anxiety, and body image among a diverse college sample: A focus on bi/multiracial women. Eating Behaviors, 11(1), 18-24. https://doi.org/10.1016/j.eatbeh.2009.08.003

Izydorczyk, B., Truong Thi Khanh, H., Lizińczyk, S., Sitnik-Warchulska, K., Lipowska, M., \& Gulbicka, A. (2020). Body dissatisfaction, restrictive, and bulimic behaviours among young women: A Polish-Japanese comparison. Nutrients, 12(3), 666. https://doi.org/10.3390/nu12030666

Jalees, T., \& de Run, E. C. (2014). Body image of Pakistani consumers. Journal of Management Science, 1(1), 16-34. https://doi.org/10.20547/jms.2014.1401102

K, Spitzer RL, Williams JB, et al; Anxiety disorders in primary care: prevalence, impairment, comorbidity, and detection. Ann Intern Med. 2007 Mar 6 146(5):317-25. https://doi.org/10.7326/0003-4819146-5-200703060-00004

Khan, A. N., Khalid, S., Khan, H. I., \& Jabeen, M. (2011). Impact of today's media on university student's body image in Pakistan: a conservative, developing country's perspective. BMC Public Health, 11(1), 379. https://doi.org/10.1186/1471-2458-11-379

Khor, G. L., Zalilah, M. S., Phan, Y. Y., Ang, M., Maznah, B., \& Norimah, A. K. (2009). Perceptions of body image among Malaysian male and female adolescents. Singapore medical journal, 50(3), 303.

Kim, N., \& Lee, J. (2019). The Associations of Appearance Comparisons with Peers and Chinese and Korean Media Figures with Thin-Ideal Internalization, Body Dissatisfaction, and the Drive for Thinness Among Female Korean-Chinese College Students in China. International Journal of Communication, 13, 24. https://doi.org/10.2224/sbp.6801

Kim, S. (2018). Eating disorders, body dissatisfaction, and self-esteem among South Korean women. Social Behavior and Personality: an international journal, 46(9), 1537-1546. https://doi.org/10.2224/sbp.6801

Kogure, G. S., Ribeiro, V. B., Lopes, I. P., Furtado, C. L. M., Kodato, S., de Sá, M. F. S., ... \& dos Reis, R. M. (2019). Body image and its relationships with sexual functioning, anxiety, and depression in women with polycystic ovary syndrome. Journal of affective disorders, 253, 385-393. https://doi.org/10.1016/j.jad.2019.05.006

Kroenke, K., Spitzer, R. L., \& Williams, J. B. (2001). The PHQ-9: validity of a brief depression severity measure. Journal of general internal medicine, 16(9), 606-613. https://doi.org/10.1046/j.15251497.2001.016009606.x

Lantz, E. L., Gaspar, M. E., DiTore, R., Piers, A. D., \& Schaumberg, K. (2018). Conceptualizing body dissatisfaction in eating disorders within a self-discrepancy framework: a review of evidence. 
Eating and Weight Disorders-Studies on Anorexia, Bulimia and Obesity, 23(3), 275-291. https://doi.org/10.1007/s40519-018-0483-4

Laporta-Herrero, I., Jáuregui-Lobera, I., Barajas-Iglesias, B., \& Santed-Germán, M. Á. (2018). Body dissatisfaction in adolescents with eating disorders. Eating and Weight Disorders-Studies on Anorexia, Bulimia and Obesity, 23(3), 339-347. https://doi.org/10.1007/s40519-016-0353-x

Levinson, C. A., \& Rodebaugh, T. L. (2012). Social anxiety and eating disorder comorbidity: The role of negative social evaluation fears. Eating behaviors, 13(1), 27-35. https://doi.org/10.1016/j.eatbeh.2011.11.006

Levnson, C. A., \& Rodebaugh, T. L. (2015). Negative social-evaluative fears produce social anxiety, food intake, and body dissatisfaction: evidence of similar mechanisms through different $\begin{array}{lll}\text { pathways. Clinical } & \text { Psychological } & \text { Science, 3(5), }\end{array}$ https://doi.org/10.1177/2167702614548891

Mahmud, N., \& Crittenden, N. (2007). A comparative study of body image of Australian and Pakistani

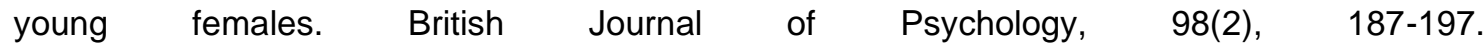
https://doi.org/10.1348/000712606X112446

Manaf, N. A., Saravanan, C., \& ZuhrAh, B. (2016). The prevalence and inter-relationship of negative body image perception, depression and susceptibility to eating disorders among female medical undergraduate students. Journal of clinical and diagnostic research: JCDR, 10(3), VC01. https://doi.org/10.7860/JCDR/2016/16678.7341

Martin, J. B. (2010). The development of ideal body image perceptions in the United States. Nutrition Today, 45(3), 98-110. https://doi.org/10.1097/NT.0b013e3181dec6a2

McLaren, L., \& Kuh, D. (2004). Women's body dissatisfaction, social class, and social mobility. Social Science and Medicine, 58, 1575-1584. https://doi.org/10.1016/S0277-9536(03)00209-0

Memon, A. A., Adil, S. E. E. R., Siddiqui, E. U., Naeem, S. S., Ali, S. A., \& Mehmood, K. (2012). Eating disorders in medical students of Karachi, Pakistan-a cross-sectional study. BMC research notes, 5(1), 84. https://doi.org/10.1186/1756-0500-5-84

Morrison, T. G., Morrison, M. A., \& Hopkins, C. (2003). Striving for bodily perfection: An explanation for the drive for masculinity in Canadian males. Psychology of Men and Masculinity, 4, 111-120. https://doi.org/10.1037/1524-9220.4.2.111

Muth, J. L., \& Cash, T. F. (1997). Body-Image Attitudes: What Difference Does Gender Make? 1. Journal of applied social psychology, 27(16), 1438-1452. https://doi.org/10.1111/j.15591816.1997.tb01607.x

Northrop, J. M. (2012). Reflecting on cosmetic surgery: body image, shame and narcissism. Routledge. https://doi.org/10.4324/9780203121511

Omori, M., Yamazaki, Y., Aizawa, N., \& Zoysa, P. D. (2017). Thin-ideal internalization and body dissatisfaction in Sri Lankan adolescents. Journal of health psychology, 22(14), 1830-1840. https://doi.org/10.1177/1359105316637665

Paans, N. P., Bot, M., Brouwer, I. A., Visser, M., \& Penninx, B. W. (2018). Contributions of depression and body mass index to body image. Journal of psychiatric research, 103, 18-25. https://doi.org/10.1016/j.jpsychires.2018.05.003

Paxton, S. J., Neumark-Sztainer, D., Hannan, P. J., \& Eisenberg, M. E. (2006). Body dissatisfaction prospectively predicts depressive mood and low self-esteem in adolescent girls and boys. Journal of clinical child and adolescent psychology, 35(4), 539-549. doi: 10.1007/s10964-005-9010-9

Polivy, J., \& Herman, C. P. (2002). Causes of eating disorders. Annual Review of Psychology, 53, 187213. https://doi.org/10.1146/annurev.psych.53.100901.135103 
Pompili, M., Girardi, P., Tatarelli, G., Ruberto, A., \& Tatarelli, R. (2006). Suicide and attempted suicide in eating disorders, obesity, and weight-image concern. Eating Behaviors, 7, 384-394. https://doi.org/10.1016/j.eatbeh.2005.12.004

Primus, M. (2014). Body dissatisfaction and males: A conceptual model. Scholarly Horizons: University of Minnesota, Morris Undergraduate Journal, 1(1), 6.

Råberg, M., Kumar, B., Holmboe-Ottesen, G., \& Wandel, M. (2010). Overweight and weight dissatisfaction related to socio-economic position, integration and dietary indicators among south Asian immigrants in Oslo. Public health nutrition, 13(5), 695-703. https://doi.org/10.1017/S1368980009991662

Rodgers, R. F. (2016). The role of the "Healthy Weight" discourse in body image and eating concerns: An extension of sociocultural theory. Eating Behaviors, 22, 194-198. https://doi.org/10.1016/j.eatbeh.2016.06.004

Salomon, I., \& Brown, C. S. (2019). The selfie generation: Examining the relationship between social media use and early adolescent body image. The Journal of Early Adolescence, 39(4), 539-560. https://doi.org/10.1177/0272431618770809

Shaheen, A., Kumar, H., Dev, W., Parkash, O., \& Rai, K. (2016). Gender Difference Regarding Body Image: A Comparative Study. Adv Obes Weight Manag Control, 4(4), 00092. https://doi.org/10.15406/aowmc.2016.04.00092

Shoraka, H., Amirkafi, A., \& Garrusi, B. (2019). Review of body image and some of contributing factors in Iranian population. International journal of preventive medicine, 10. https://doi.org/10.4103/ijpvm.IJPVM_293_18

Silva, D., Ferriani, L., \& Viana, M. C. (2019). Depression, anthropometric parameters, and body image in adults: a systematic review. Revista da Associação Médica Brasileira, 65(5), 731-738. https://doi.org/10.1590/1806-9282.65.5.731

Spitzer, R. L., Williams, J. B. W., \& Kroenke, K. (1990). Instruction manual: Instructions for patient health questionnaire (PHQ) and GAD-7 measures. PHQ and GAD-7 instructions.

Stice, E., \& Shaw, H. E. (2002). Role of body dissatisfaction in the onset and maintenance of eating pathology: A synthesis of research findings. Journal of Psychosomatic Research, 53, 985-993. https://doi.org/10.1016/S0022-3999(02)00488-9

Stice, E., Hayward, C., Cameron, R. P., Killen, J. D., \& Taylor, C. B. (2000). Body-image and eating disturbances predict onset of depression among female adolescents: a longitudinal study. Journal of abnormal psychology, 109(3), 438. https://doi.org/10.1037/0021-843X.109.3.438

Suhail, K. (2002). Prevalence of eating disorders in Pakistan: relationship with depression and body shape. Eating and Weight Disorders-Studies on Anorexia, Bulimia and Obesity, 7(2), 131-138. https://doi.org/10.1007/BF03354439

Swinson, J. (2011, August 10). False beauty in advertising and the pressure to look 'good'. Retrieved from: http://edition.cnn.com/2011/OPINION/08/08/swinson.airbrushing.ads/index.html

Tariq, M., \& ljaz, T. (2015). Development of Body Dissatisfaction Scale for university students. Pakistan Journal of Psychological Research, 30(2), 305.

Tiggemann, M. (2004). Body image across the adult life span: Stability and change. Body Image, 1, 29 41. https://doi.org/10.1016/S1740-1445(03)00002-0

Tiggemann, M. (2011). Sociocultural perspectives on human appearance and body image. In T. F. Cash \& L. Smolak (Eds.), Body image: A handbook of science, practice and prevention. London, England: Guilford Press. https://doi.org/10.1016/B978-0-12-384925-0.00120-6

Tsai, G., Curbow, B., \& Heinberg, L. (2003). Sociocultural and Developmental Influences on Body Dissatisfaction and Disordered Eating Attitudes and Behavious of Asian Women. The Journal of 
Nervous and Mental 309-318. https://doi.org/10.1097/01.NMD.0000066153.64331.10

Uchôa, F. N. M., Uchôa, N. M., Daniele, T. M. D. C., Lustosa, R. P., Garrido, N. D., Deana, N. F., ... \& Alves, N. (2019). Influence of the mass media and body dissatisfaction on the risk in adolescents of developing eating disorders. International journal of environmental research and public health, 16(9), 1508. https://doi.org/10.3390/ijerph16091508

Van den Berg, P., Paxton, S. J., Keery, H., Wall, M., Guo, J., \& Neumark-Sztainer, D. (2007). Body dissatisfaction and body comparison with media images in males and females. Body Image, 4(3), 257-268. https://doi.org/10.1016/j.bodyim.2007.04.003

Vannucci, A., \& Ohannessian, C. M. (2017). Body image dissatisfaction and anxiety trajectories during adolescence. Journal of Clinical Child \& Adolescent Psychology, 1-11. https://doi.org/10.1080/15374416.2017.1390755

Vartanian, L. R. 2. (2012). Self-discrepancy theory and body image. Encyclopedia of body image and human appearance, 2, 711-717. https://doi.org/10.1016/B978-0-12-384925-0.00112-7

Wardle, J., Bindra, R., Fairclough, B., \& Westcombe, A. (1993). Culture and body image: Body perception and weight concern in young Asian and Caucasian British women. Journal of Community \& Applied Social $\quad$ Psychology, 3(3), $173-181$. https://doi.org/10.1002/casp.2450030302

Wertheim, E. H., Koerner, J., \& Paxton, S. J. (2001). Longitudinal predictors of restrictive eating and bulimic tendencies in three different age groups of adolescent girls. Journal of Youth and Adolescence, 30(1), 69-81. https://doi.org/10.1023/A:1005224921891

Winter, V. R., Combs, K. M., \& Ward, M. (2018). An investigation of the association between foster care, body image, and BMI: A propensity score analysis. Children and Youth Services Review, 84, 8285. https://doi.org/10.1016/j.childyouth.2017.11.021

Zachrisson, H. D., \& Skårderud, F. (2010). Feelings of insecurity: Review of attachment and eating disorders. European Eating Disorders Review, 18(2), 97-106. https://doi.org/10.1002/erv.999 